\title{
The copper catalysed reaction of sodium methoxide with aryl bromides : a mechanistic study leading to a facile synthesis of anisole derivatives
}

Citation for published version (APA):

Aalten, H. L., Koten, van, G., Grove, D. M., Kuilman, T., Piekstra, O. G., Hulshof, L. A., \& Sheldon, R. A. (1989). The copper catalysed reaction of sodium methoxide with aryl bromides' a mechanistic study leading to a facile synthesis of anisole derivatives. Tetrahedron, 45(17), 5565-5578. https://doi.org/10.1016/S0040-4020(01)895028

DOI:

10.1016/S0040-4020(01)89502-8

Document status and date:

Published: 01/01/1989

Document Version:

Publisher's PDF, also known as Version of Record (includes final page, issue and volume numbers)

Please check the document version of this publication:

- A submitted manuscript is the version of the article upon submission and before peer-review. There can be important differences between the submitted version and the official published version of record. People interested in the research are advised to contact the author for the final version of the publication, or visit the $\mathrm{DOI}$ to the publisher's website.

- The final author version and the galley proof are versions of the publication after peer review.

- The final published version features the final layout of the paper including the volume, issue and page numbers.

Link to publication

\footnotetext{
General rights

- You may freely distribute the URL identifying the publication in the public portal. follow below link for the End User Agreement:

www.tue.nl/taverne

\section{Take down policy}

If you believe that this document breaches copyright please contact us at:

openaccess@tue.nl

providing details and we will investigate your claim.
}

Copyright and moral rights for the publications made accessible in the public portal are retained by the authors and/or other copyright owners and it is a condition of accessing publications that users recognise and abide by the legal requirements associated with these rights.

- Users may download and print one copy of any publication from the public portal for the purpose of private study or research.

- You may not further distribute the material or use it for any profit-making activity or commercial gain

If the publication is distributed under the terms of Article 25fa of the Dutch Copyright Act, indicated by the "Taverne" license above, please 


\title{
THE COPPER CATALYSED REACTION OF SODIUM METHOXIDE WTTH ARYL BROMIDES. A MECHANISTIC STUDY LEADING TO A PACILE SYNTHESIS OF ANISOLE DERIVATIVES
}

\author{
Henk L. Aalten, a Gerard van Koten, *, a, b David M. Grove,c \\ Thijs Kuilman, Onno G. Piekstra, Lumbertus A. Hulshof d and Roger A. Sheldond
}

a Anorganisch Chemisch Laboratorium, J.H. van 't Hoff Instituut, University of Amsterdam, Nieuwe Achtergracht 166, 1018 WV Amsterdam, The Netherlands

b Present address; Laboratory for Organic Chemistry, Dept.of Metal-Mediated Synthesis, University of Utrecht, Padualaan 8, 3584 CH Utrecht, The Netherlands.

c See b.

d Andeno B.V., p.o. box 81, 5900 AB Venlo.

(Received in UK 14 March 1989)

\begin{abstract}
The copper catalysed reaction of unactivated aryl bromides with sodium methoxide has been investigated by studying a number of parameters (copper catalyst, cosolvent, concentration and relative ratio of the reactants, additives and aryl bromide substituents) which influence this reaction. The ipso-substitution reaction was found to proceed via an intimate electron transfer mechanism involving a cuprate-like intermediate, $\mathrm{Na}\left[\mathrm{Cu}(\mathrm{OMe})_{2}\right] . \mathrm{A}$ convenient synthesis of methyl aryl ethers from aryl bromides and concentrated sodium methoxide solutions in dimethyl formamide and methanol is presented. Also an attempt to extend this reaction to the use of chlorine derivatives was made.
\end{abstract}

\section{INTRODUCTION}

Previous investigations aimed at the synthesis of methyl aryl ethers from unactivated substrates (substrates without strong electron withdrawing substituents) have had limited success. Methods for the introduction of methoxy substituents onto aryl rings are important because several methyl aryl ethers are used as intermediates for the synthesis of pharmaceutical products. 1,3,5-Trimethoxybenzene for instance is used in the synthesis of some 
vasoactive drugs. Moreover methyl aryl ethers are possible intermediates in alternative phenol syntheses since their hydrolysis would yield phenol derivatives. 1

The most straightforward introduction of a methoxide substituent is the reaction of an aryl halide with methoxide ion, eq 1.

$$
\mathrm{ArX}+\mathrm{MeO}^{-} \longrightarrow \text { ArOMe }+\mathrm{X}^{-}
$$

This synthesis of methyl aryl ethers is successful with activated aryl substrates (aryl rings having strong electron withdrawing substituents), where the ipso-substitution proceeds via an SNAr mechanism. ${ }^{2}$ Furthermore, methyl aryl ethers are accessible via the reaction of unactivated aryl chlorides through substitution of the halide by methoxide ion in hexamethylphosphoric acid triamide (HMPA). ${ }^{3}$ This procedure however is not very convenient (vield $50 \%$ of anisole in $18.5 \mathrm{~h}$ from chlorobenzene; HMPA is a cancer suspect agent).

Methyl aryl ethers can also be synthesized from unactivated aryl bromides and iodides by a copper catalysed ipso-substitution reaction. The competition between the reduction and the substitution reaction of several aryl bromides and iodides in methanol/collidine catalysed by $\mathrm{CuI}$ at $100-120^{\circ} \mathrm{C}$ was investigated by Bacon and coworkers. ${ }^{4}$ They found, firstly, that the amount of reduction increased when methoxy substituents were present ortho to the halogen atom and, secondly, that aryl iodides were more responsive to reduction than the bromides. Their best result was the total bromide substitution of 1-bromonaphthalene by ethoxide ion in 6 hours (with methoxide ion they reached $96 \%$ substitution). $4 c$

Litvak and Shein investigated the mechanism of the copper catalysed reaction of aryl bromides with sodium methoxide in competition with the uncatalysed process in methanol/pyridine using low methoxide concentrations $(<1.0 \mathrm{M}) .^{5}$ They found that the copper-catalysed ipso-substitution reaction was first order in aryl bromide and catalyst, while the concentration of the sodium methanolate was irrelevant. They made a Hammett correlation that showed the influence of substituents in the copper catalysed reaction was relatively small $(\rho=0.48)$ compared to their influence in the uncatalysed SNAr substitution reaction $(\rho=5.0)$. They proposed a mechanism that combined a radical reaction with a 4-centre substitution process (Scheme 1). Their study lacked the translation of their mechanistic investigations into a useful synthetic procedure.

Scheme 1

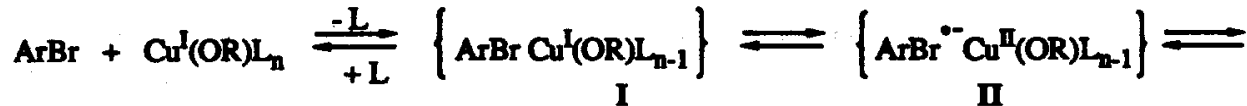

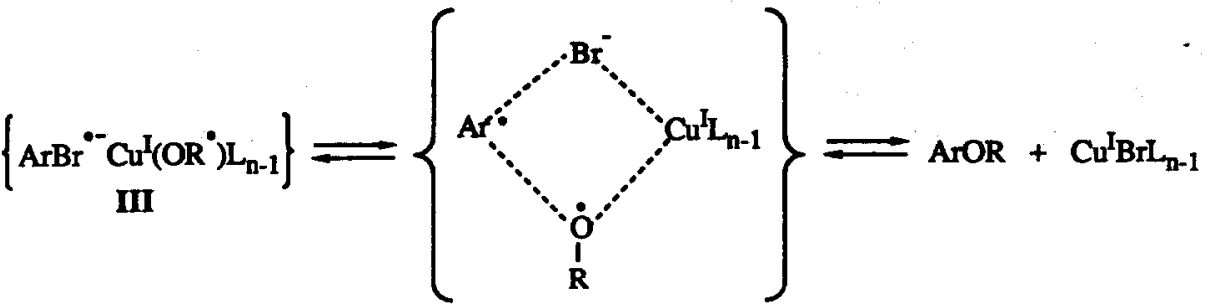

$$
\begin{aligned}
& \text { IV }
\end{aligned}
$$


Whitesides et al. showed that $\mathrm{Cu}(\mathrm{I})$ alkoxides, formed by the reaction of methylcopper(I) with alcohols, react at room tempernture with aryl bromides and iodides to give ethers. 6 This reaction is synthetically inconvenient but the result clearly indicates that $\mathrm{Cu}(\mathrm{D})$ alkoxides are able to transfer an alkoxy group to an aryl substrate. Copper(I) alkoxides are therefore likely to be intermediates in the copper catalysed reaction of sodium methoxide with aryl halides.

Our study concerns a thorough investigation of various parameters that influence the copper catalysed reaction of aryl bromides with methoxide. The aim of this study was, $i$, the development of a convenient synthesis of methyl aryl ethers from aryl bromides, $i i$, to elucidate the mechanism of this reaction and, $i i i$, hopefully an extension of this reaction to aryl chloride substrates. The use of the latter as starting material is economically and environmentally favourod since aryl chlorides are cheaper in the production process and sodium chloride instead of sodium bromide is the waste product.

In the course of our investigation it has been found that the concentration of sodium methoxide is very important (contrary to the conclusion of Litvak and Shein) and that the reaction proceeds via an intimate electron transfer mechanism involving a cuprate-like intermediate, $\mathrm{Na}[\mathrm{Cu}(\mathrm{OMe}) 2]$.

\section{RESULTS and DISCUSSION}

The copper catalysed nucleophilic aromatic substitution reaction of aryl bromides with sodium methoxide was studied by investigating the influence of several reaction parameters, namely $i$, the nature (oxidation state/ anion) and concentration of the copper catalyst, $i i$, the cosolvents, $i i i$, the concentration and number of equivalents of the nucleophile, $i v$, the bromide concentration, and $v$, the aryl bromide substituent effects. The reactions that are carried out, are summarized in Table I and their course was followed by taking samples which were analysed by GLC. The conversion percentages of bromobenzene to anisole after $6 \mathrm{~h}$ (unless stated otherwise) are listed in Table I. Other results of several reactions are summarized in Tables II and III and in Figures 1 and 2.

The copper catalyst

The nature of the copper catalyst.

Although the valence of the reactive copper catalyst in copper catalysed nucleophilic substitution reactions is generally considered to be +1 (see ref. 7) several copper catalysts with copper in different oxidation states were investigated and the influence of aging of various copper(I) catalysts studied.

A comparison of the first four entries clearly shows that the age of the $\mathrm{Cu}(\mathrm{I}) \mathrm{Br}$ is unimportant; the same reactivity was found for commercial $(1,3)$ as for freshly prepared copper(I) bromide $(2,4)$. This indicates that the oxidation state (or purity) of the copper catalyst used is not particularly relevant since copper(I) bromide is known to disproportionate into copper(II) bromide and copper metal or oxidize to copper(II) bromide when it is stored for long periods. 


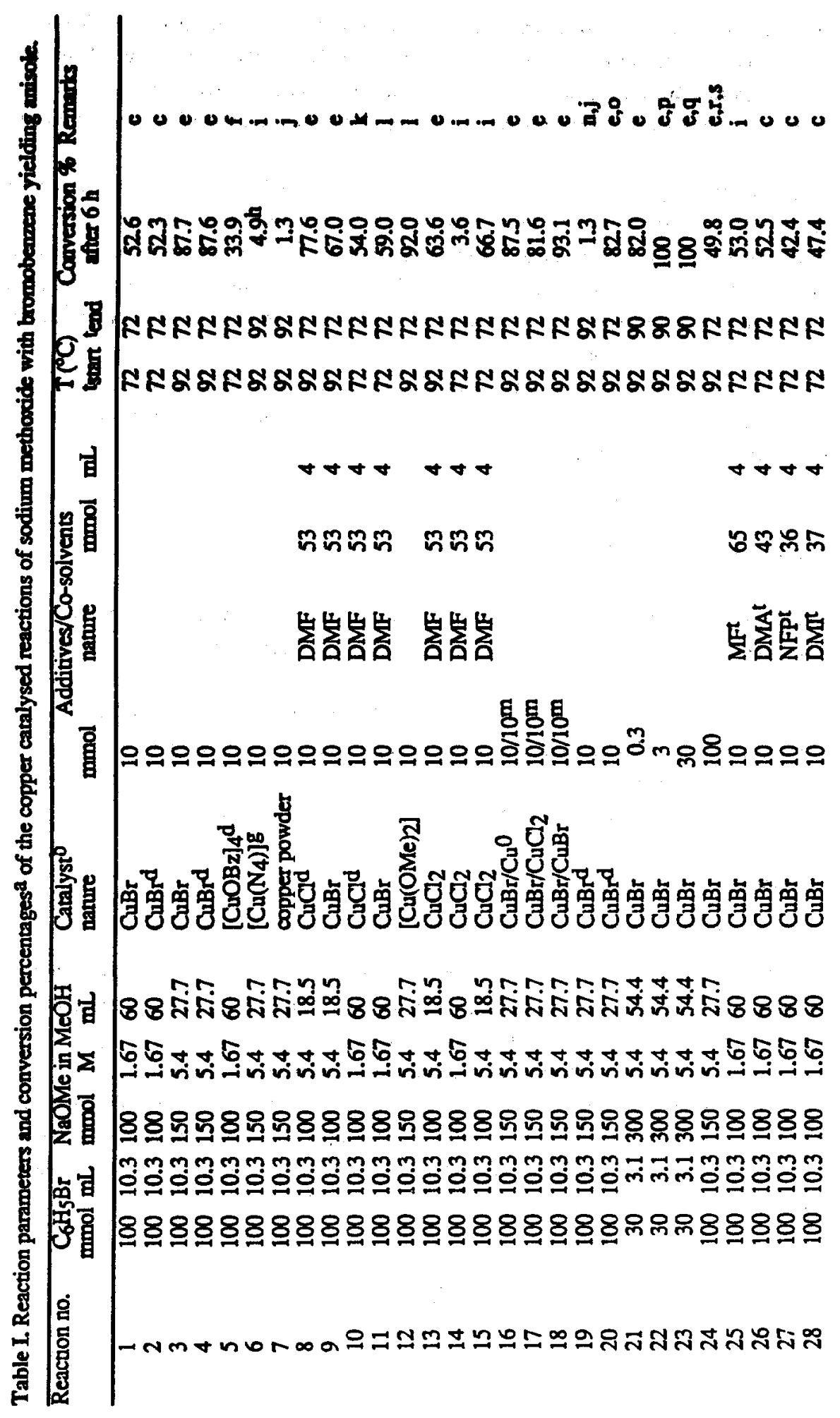




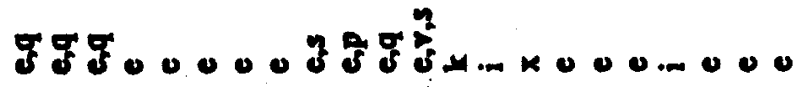

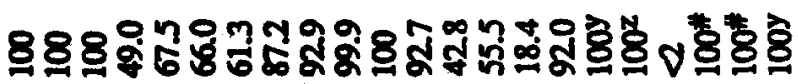

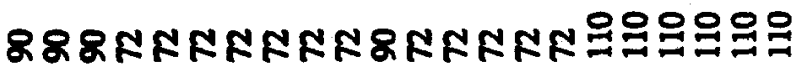

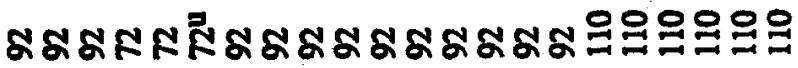

영융형++

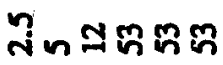

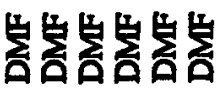

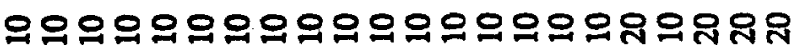

nน

क⿻

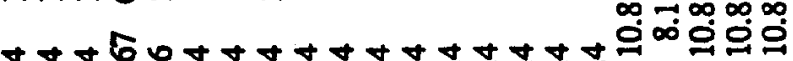

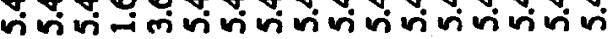

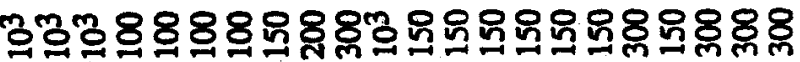
mmmmmmmmmmmmmmmmomo

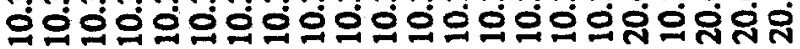

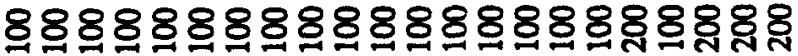

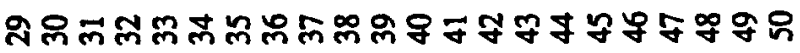
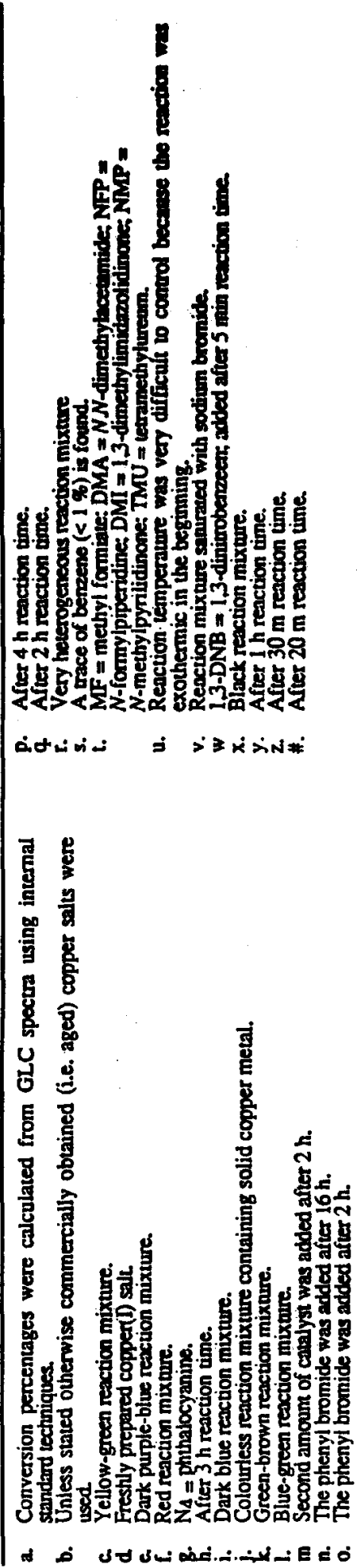
When copper(I) benzoate was used as a catalyst (5) the reaction proceeded more slowly than when catalysed by copper(I) bromide $(1,2)$. When copper(II) phthalocyanine (6) or copper powder (7) were used as catalysts the yield of anisole is very poor compared to the identically executed copper(I) bromide catalyeed reactions $(3,4)$.

The reactivity of copper(I) chloride and copper(I) bromide was comparable in both concentrated sodium methoxide (used as a $5.4 \mathrm{M}$ solution in methanol, reactions 8 and 9) and in diluted sodium methoxide (used as a $1.6 \mathrm{M}$ solution in methanol, reactions 10 and 11 ).

When copper(II) salts were used, the substitution reaction was highly dependent on the concentration of the sodium methoxide in the reaction medium. If the concentration of sodium methoxide was high (5.4 M) then copper(II) methoxide (12) and copper(II) chloride (13) were effective catalysts (92.0 and $63.6 \%$ yields, respectively, after $6 \mathrm{~h}$ ). However, if the concentration of sodium methoxide was low (1.67 M) copper(II) chloride (14) hardly catalysed the substitution reaction (yield 3.6\% after $6 \mathrm{~h}$ ).

The temperature (reflux) of the concentrated sodium methoxide reaction (13) was higher $\left(\mathrm{T}=92^{\circ} \mathrm{C}\right)$ than the diluted sodium methoxide reaction $\left(14 ; \mathrm{T}=70^{\circ} \mathrm{C}\right.$ ). The former reaction was also executed at $70^{\circ} \mathrm{C}$ to exclude an unexpected extreme temperature effect. This reaction (15) gave a comparable amount of anisole as reaction 13 $(66.7 \%, 6 \mathrm{~h})$ and therefore it is clear that the efficacy of copper(II) chloride as catalyst is determined by the methoxide concentration and not by the reaction temperature. The difference between reaction 13 and 15 was that reaction 13 was very fast in the beginning and after one hour already $50 \%$ bromobenzene had reacted while this was only $16 \%$ in the low temperature reaction (15).

To further elucidate the reactive oxidation state of the copper catalyst in the substitution reaction more copper catalyst was added after a reaction time of 2 hours. When copper powder was added (16) the substitution reaction was not influenced. Copper(II) chloride (17) retarded the substitution reaction a little while copper(I) bromide (18) accelerated the reaction in the first $\mathbf{3 0} \mathrm{min}$ after its addition (see Figure 1). These findings indicate that the reactive copper catalyst is in the +1 oxidation state. Copper(II) salts are nevertheless able to catalyse the substitution reaction in concentrated sodium methoxide. This is only possible when reduction to copper(I) (by concentrated sodium methoxide) occurs.

The influence of concentrated sodium methoxide solutions on the oxidation state of the copper catalyst was further investigated by postponed addition of bromobenzene to a mixture of copper(I) bromide and concentrated sodium methoxide (5.4 $\mathrm{M}$ in methanol) at $92^{\circ} \mathrm{C}$. When after 16 hours (19) bromobenzene was added to this mixture, a copper metal coloured suspension, formation of anisole was not found. When bromobenzene was added after 2 hours (20), however, just a slightly lower conversion to anisole was found $(82.7 \%, 6 \mathrm{~h})$ compared to the normal addition reaction $(4,87.6 \%)$.

The formation of unreactive zerovalent copper metal in reaction 19 can be readily understood. In hard coordinating solvents copper(I) salts generally undergo valence disproportionation to zerovalent copper and copper(II). The copper(II) salts formed can then be reduced by the concentrated sodium methoxide solution to copper(I) (vide supra). The repetition of this reaction sequence (Scheme 2) finally results in only zerovalent copper being present. These findings indicate once more that concentrated sodium methoxide solutions are able to reduce copper(II) to copper(I) species which are then able to catalyse the reaction. 
Figure 1. The progress of the CuBr catnlyed reaction of phenyl bromide with sodium methoxide when various copper conthining species are added after 2 hours.

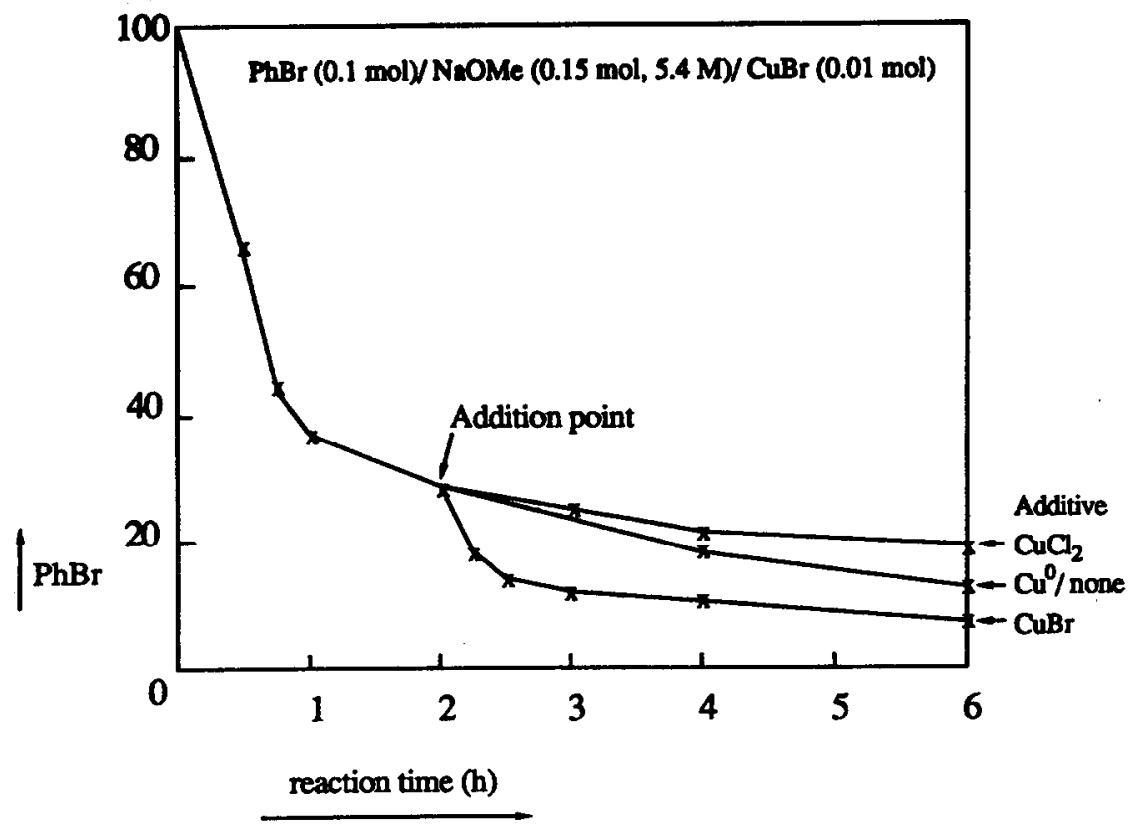

Scheme 2

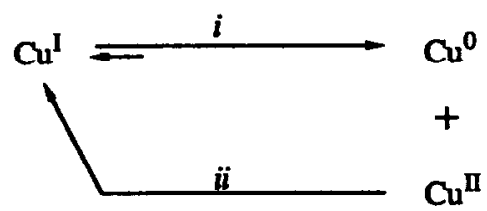

i. solvent induced valence disproportionation

ii. reduction of $\mathrm{Cu}^{\mathrm{n}}$ concentrated $\mathrm{NaOMe}$

The concentration of the copper catalyst.

The results of reactions 21-23 in which the amount of copper catalyst added to the reaction was varied showed that the reactions proceeded faster with increasing catalyst concentration (see Table II). The increase in reaction rate, however, appeared to be non-linear (a ten-fold increase in catalyst concentration increases the reaction rate respectively, from $7.26 \times 10^{-5} \mathrm{~s}^{-1}$ (reaction 21) to $4.19 \times 10^{-4} \mathrm{~s}^{-1}$ (22) to $8.14 \times 10^{-4} \mathrm{~s}^{-1}$ (23)).

The results of reaction 24 disproves the suggestion that any increase in copper catalyst, with respect to sodium methoxide and bromobenzene, should improve the substitution reaction (ratio $\mathrm{NaOMe} / \mathrm{PhBr} / \mathrm{Cu}(\mathrm{l}) \mathrm{Br}=1.5 / 1 / 1)$. The amount of substitution product in this reaction after $6 \mathrm{~h}$ was only $49.8 \%$ (100\% after $2 \mathrm{~h}$ for reaction 23). This behaviour indicates that copper(I) methoxide, presumably the effective catalyst, is formed by a methathesis reaction between $\mathrm{Cu}(\mathrm{I}) \mathrm{Br}$ and $\mathrm{NaOMe}(\mathrm{eq} 2$ ) and that it is not able to transfer its methoxide ligand to the aryl 
nucleus but that the substitution of the aromatic bromine atom requires additional sodium methoxide. Since we have in reaction 24 only 0.5 equivalent of $\mathrm{NaOMe}$ left (with respect to bromobenzene) after the quantitative formation of copper(I) methoxide, it is only possible to attain $50 \%$ (49.8\% observed) product formation.

$$
\mathrm{Cu}(\mathrm{I}) \mathrm{Br}+\mathrm{NaOMe} \longrightarrow \mathrm{Cu}(\mathrm{I}) \mathrm{OMe}+\mathrm{NaBr}
$$

Table II. The effect of the concentration of the catalyst.a,b

\begin{tabular}{llllll}
\hline Reaction no. & $\begin{array}{l}\text { [CuBr }] \\
(\mathrm{mol} / \mathrm{L})\end{array}$ & \multicolumn{2}{l}{ Conversion \% after } & $\mathbf{k} \times 10^{-4}$ & corr. coeff. \\
& $30 \mathrm{~min}$ & $60 \mathrm{~min}$ & $\left(\mathrm{~s}^{-1}\right)$ & \\
\hline 21 & 0.0052 & 6.3 & 17.3 & 0.726 & 0.9950 \\
22 & 0.052 & 54.3 & 81.5 & 4.19 & 0.9991 \\
23 & 0.52 & 76.2 & 94.9 & 8.14 & 0.9999 \\
\hline
\end{tabular}

a. When the copper catalyst was added, the reaction mixture became deeply coloured. Therefore, it was difficult to determine if the reactions were homogeneous of not. Our data are treated as if obtained from homogeneous mixtures.

b. First order kinetics assumed for bromobenzene. 5

\section{The cosolvent}

Cosolvents in copper catalysed reactions are considered to $i$, act as ligands that increase the solubility of the copper(I) catalyst and/or $i i$, stabilize the reactive copper(I) oxidation state (thereby increasing the reactivity and/or lifetime of the catalyst). Compared with the result of the standard substitution reaction 1 the only co-solvent found to have a positive effect is DMF (11) while the other cosolvents either have no effect (methyl formiate (25), $N, N$-dimethylacetamide (26)) or retard the substitution reaction ( $N$-formylpiperidine (27), 1,3-dimethylimidazolidone (28)).

The positive effect of DMF as a cosolvent was further investigated in reactions using 10 equivalents of sodium methoxide (reactions 29-31; compare with 22). It was found that increasing the DMF : copper(I) bromide ratio from 0.25 (29) to $0.5(30)$ to $1.2(31)$, the conversion after 15 minutes increased from $10 \%$ to $16 \%$ to $21 \%$, respectively. After prolonged reaction times, however, the conversions became similar.

\section{The nucleophile}

The concentration of sodium methoxide.

Since the sodium methoxide concentration is found to have a large influence on the copper(II) chloride catalysed reactions we have also investigated its influence on the copper(I) bromide catalysed reactions (reactions 32-34). These reactions were all carried out at $72{ }^{\circ} \mathrm{C}$ to exclude temperature effocts though the temperature of reaction 34 (using 5.4 M NaOMe in methanol) proved difficult to control since the reaction was very exothermic. 
The reaction with $1.8 \mathrm{M}$ sodium methoxide solution in methanol (32) yielded less anisole than the reactions with $3.6 \mathrm{M}$ or $5.4 \mathrm{M}$ sodium methoxide (33 and 34) that reached comparable conversions after 6 hours. Reaction 34 , however, proceeded faster in the beginning than reaction 33 (e.8. after $15 \mathrm{~min}$ the conversions are $34 \%$ and $25 \%$ respectively).

The explanation for these results is that the (re)formation of the active catalyst is only very effective in concentrated sodium methoxide reaction mixtures. This conclusion was already reached from the results of the influence of the sodium methoxide concentration on the copper(II) chloride catalysed reactions (vide supra). It is noteworthy that the substitution reactions in concentrated sodium methoxide solutions $(5.4 \mathrm{M})$ all proceed very quickly in the beginning (i.e. it takes ca. 30 min until a conversion of about $50 \%$ is reached) and then slow down considerably. The explanation for this is that as the sodium methoxide reacts, its concentration drops until it is eventually below a critical level where the reformation of the active copper catalyst becomes very slow.

Our conclusions contradict with those of Litvak and Shein 5 who stated that the substitution reaction was independent of the concentration of sodium methoxide. It must be noted however that they generally used low $(<1.0 \mathrm{M})$ sodium methoxide concentrations.

The number of equivalents of sodium methoxide.

In reactions 35-39 using $100 \mathrm{mmol}$ of bromobenzene (and $10 \mathrm{mmol}$ of copper(I) bromide) it was found that increasing the relative number of equivalents of sodium methoxide with respect to bromobenzene from 1:1 to 10:1 had a positive influence on the progress of the reaction when the mixture was kept at constant reflux. In the first $15 \mathrm{~min}$ of these reactions there is not a great difference conversion percentages; they range from 32.7 to $40.0 \%$. However, over more prolonged reaction times the substitution reaction proceeds better when the amount of sodium methoxide present is higher.

The conversions in these experiments depend on two factors, namely the reflux temperature and the methoxide concentration; both of which change as the reaction proceeds. In particular at low $\mathrm{NaOMe}$ to bromobenzene ratios the reflux temperature decreases rapidly (from 92 to $75^{\circ} \mathrm{C}$ in the initial $30 \mathrm{~min}$ ). This is primarily due to the release of "solvent cage bonded" methanol from sodium methoxide. When the $\mathrm{NaOMe}$ to $\mathrm{PhBr}$ ratio is initially 10:1 the reflux temperature drops only $2^{\circ} \mathrm{C}$ in two hours. Regarding the $\mathrm{NaOMe}$ concentration we have already shown that when this drops below a critical value the reformation of the active copper(I) catalyst slows down and consequently the reaction proceeds more slowly (vide supra).

\section{The bromide concentration}

One of the products of the copper catalysed substitution reaction of sodium methoxide with bromobenzene was sodium bromide (besides unidentified copper salts, anisole and traces of benzene ( $<1 \%$, only found in reactions 24, 37 and 40, see Table I); biphenyl was never found). The possible reversibility of the copper catalysed aromatic substitution reaction of aryl bromides with sodium methoxide was investigated by adding bromide containing salts to the reaction mixture (reactions 40-42). Addition of sodium bromide had little effect on the reaction but this is probably due to the limited solubility of this salt under the conditions employed. When either lithium bromide (41) or cobalt(II) bromide (42) was added, the reaction was significantly retarded. This result is 
ambiguous and could be explained by either $I$, a reventible reaction or $I$, formation of mixed metal species which are presumably less active catalysts for the substitution reaction.

\section{Substituent effects}

Substituent effects in the copper catalysed ipso-substitution reaction of sodium methoxide with aryl bromides were investigated by making a Hammett correlation based on competition reactions between bromobenzene and various aryl bromides. The aryl ring substituents used were $\mathrm{p}-\mathrm{OMe}, \mathrm{m}-\mathrm{OMe}, \mathrm{p}-\mathrm{Me}, \mathrm{m}-\mathrm{Me}, \mathrm{p}-\mathrm{Cl}$ and $\mathrm{m}-\mathrm{Cl}$. The results of the competition reactions with m-methylbromobenzene were not included in the final Hammett correlation since they showed too large a discrepancy with each other and with the other measurements. Ortho substituted aryl bromide derivatives were excluded because of their possible steric and chelating consequences. Strong electron accepting groups were also not used because then the uncatalysed reaction would begin to play an important role. 5

The Hammett correlation was measured by competition experiments using 10 equivalents, with respect to the total amount of aryl halogenide present, of sodium methoxide (see experimental). These pseudo first order reactions gave a $p$ value of 0.49 (corr. coef. $=0.9032$ ) see Table III, Figure 2). This value indicates that the slow reaction step, in the product forming reaction sequence, has a minor nucleophilic nature ( $p$ values found for the SNAr reactions are always $>2$ ). The $p$ value we found is in good agreement with the value found by Litvak and Shein for the copper catalysed reaction in diluted sodium methoxide solution in methanol/pyridine $(\rho=0.48)$.

Table III. The reactivity of several substituted aryl bromides relative to phenyl bronide in the copper catalysed reaction of aryl bromides with sodium methoxide.

\begin{tabular}{lrll}
\hline substituent & \multicolumn{1}{l}{$\sigma$} & $\mathbf{k} \times / k_{\mathbf{H}}(\mathrm{s}$ dev $)$ & $\log \mathbf{k} \times k_{\mathbf{H}}$ \\
\hline p-OMe & -0.28 & $0.5636(0.1572)$ & -0.2490 \\
m-OMe & 0.10 & $1.1890(0.1425)$ & 0.0752 \\
p-Me & -0.14 & $0.9091(0.0805)$ & -0.0414 \\
p-Cl & 0.24 & $1.1302(0.0875)$ & 0.0531 \\
m-Cl & 0.37 & $1.3264(0.1430)$ & 0.1227 \\
\hline
\end{tabular}

The reaction mechanism
Figure 2. The dependence of $\log k_{X} / \log k_{H}$ on the $\sigma$ constants of the substituents

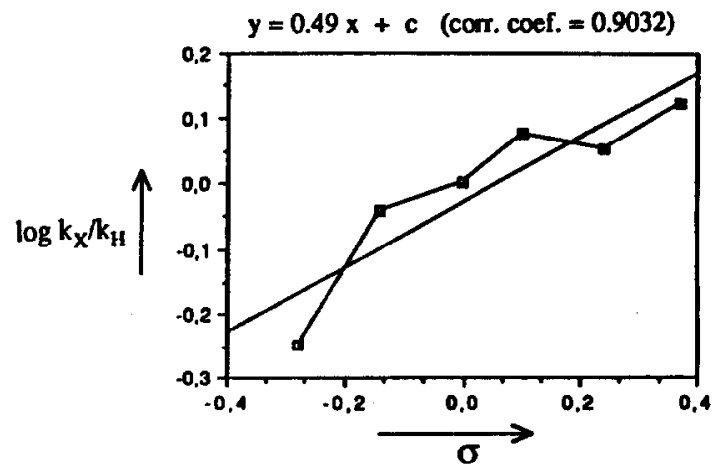

From our study of the parameters influencing the copper catalysed nucleophilic aromatic substitution reaction of sodium methoxide with unactivated aryl bromides it was concluded that $i$, the reactive catalyst is copper(I) methoxide which was, however, not able to transfer its methoxide ligand to the aryl moiety (it needed at least another equivalent of sodium methoxide to substitute the bromine atom on the aryl ring), $i i$, the reaction order in copper catalyst under our conditions is smaller than 1 , iii, the conversion of the reaction increased with increased ratio of sodium methoxide to aryl bromide and $i v$, the $\rho$ value found $(0.49)$ indicates that the slow reaction step, in the product forming reaction sequence, has a minor nucleophilic nature. 
Based on these conclusions the possible mechaniems for this reaction can be restricted to two, l.e. either an SRN1 or an intimate electron transfer mechanism. The mechanism was further investigated by the addition of radical scavengers to discover whether it had a free radical character or not. When 1,3-dinitrobenzene (1,3-DNB) was added (1 equivalent with respect to the copper catalyst) five minutes after the substitution reaction was started, the reaction was inhibited completely (43). This effect can either be due to 1,3-DNB scavenging the radical reaction or its binding to the copper catalyst making it unreactive. In contrast the addition of cumene had no effect on the reaction and no $\alpha$-methylstyrene was formed (44). This indicates that the copper catalysed substitution reaction proceds rather via an intimate eloctron transfer mochanism than via a free radical mochanism.

We propose that cuprate-like intermediates e.g. $\mathrm{Na}+[\mathrm{Cu}(\mathrm{OMe}) 2]^{-}$, are the reactive catalysts in the copper catalysed substitution reactions of aryl bromides using concentrated sodium methoxide (see Scheme 3 ). After the formation of the reactive cuprate catalyst the next step in the reaction sequence must be the formation of an aggregate between the copper-centre and the aryl moiety. This aggregate can be formed by the coordination of the aryl moiety to the copper atom via its $\pi$-electrons or via the n-electron of the halogen atom. The possibility of the $\pi$-electron coordination mode is illustrated by several known complexes of aryl rings towards copper(I) salts. 9,10 The next step in the reaction will be the transfer of electron density ( $\leq 1$ electron) from the copper(I) atom to the aryl moiety. This electron density initiates the weakening of the carbon-bromine bond when it is situated in the $\sigma^{*}$-orbital. 11 The complete bond breakage between the bromine and the carbon atom can then proceed via two reaction routes; $\mathbf{A}$, via consecutive oxidative addition-reductive elimination reactions or $\mathbf{B}$, via a concerted process. The oxidative addition-reductive elimination reaction path seems unlikely since then trivalent copper intermediates would have to be formed. This is not likely to happen in a reaction medium where even copper (II) is reduced to copper(I).

The release of an aryl bromide radical anion from intermediate IV must be responsible for the formation of benzene that is found as the only minor side-product in our reactions. From this radical anion the bromide anion dissociates and the aryl radical than forms benzene by interaction with the solvent.

The order in $\mathrm{Cu}(\mathrm{I}) \mathrm{Br}$ found for these reactions $(<1)$ is explained by a monomer-dimer equilibrium for $\mathrm{Na}+[\mathrm{Cu}(\mathrm{OMe}) 2]-$. The monomer would then be the reactive catalytic species while the dimer is unreactive (eq 3 ).
$2\left[\mathrm{Na}^{+}[\mathrm{Cu}(\mathrm{OMe})]^{-}\right]$ reactive

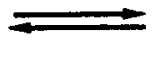

\section{Synthetic considerations}

The knowledge obtained about the mechanism of the copper catalysed nucleophilic aromatic substitution reaction of sodium methoxide with bromobenzene has been used to develop a convenient synthesis of anisole (or its derivatives). The reaction kinetics indicate that the concentration of the sodium methoxide in methanol must be as high as possible for a fast reaction. Since DMF appeared to be a useful cosolvent this was used as such.

The successful high yield synthesis of anisole is carried out by adding $150 \mathrm{mmol}$ of sodium methoxide (27.7 mL of a $5.4 \mathrm{M}$ solution in methanol), bromobenzene $(10.3 \mathrm{~mL}, 100 \mathrm{mmol})$ and DMF (25 mL) to a reaction vessel, heating the mixture to a reflux temperature of $110^{\circ} \mathrm{C}$, with methanol being allowed to distil out of the reaction vessel, followed by the addition of copper(I) bromide ( $1.44 \mathrm{~g}$; reaction 45$)$. Quantitative formation of anisole 
$\mathrm{NaOM} \theta+\mathrm{CuBr} \rightarrow \mathrm{CuOMe}+\mathrm{NaBr} \stackrel{\mathrm{NaOM} \theta}{\longrightarrow} \mathrm{Na}\left[\mathrm{Cu}^{\prime}(\mathrm{OM} \theta)_{2}\right]$ I II

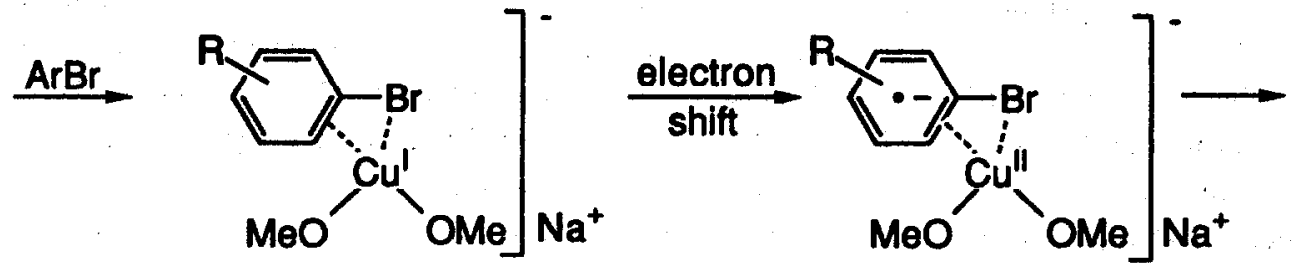

III

IV

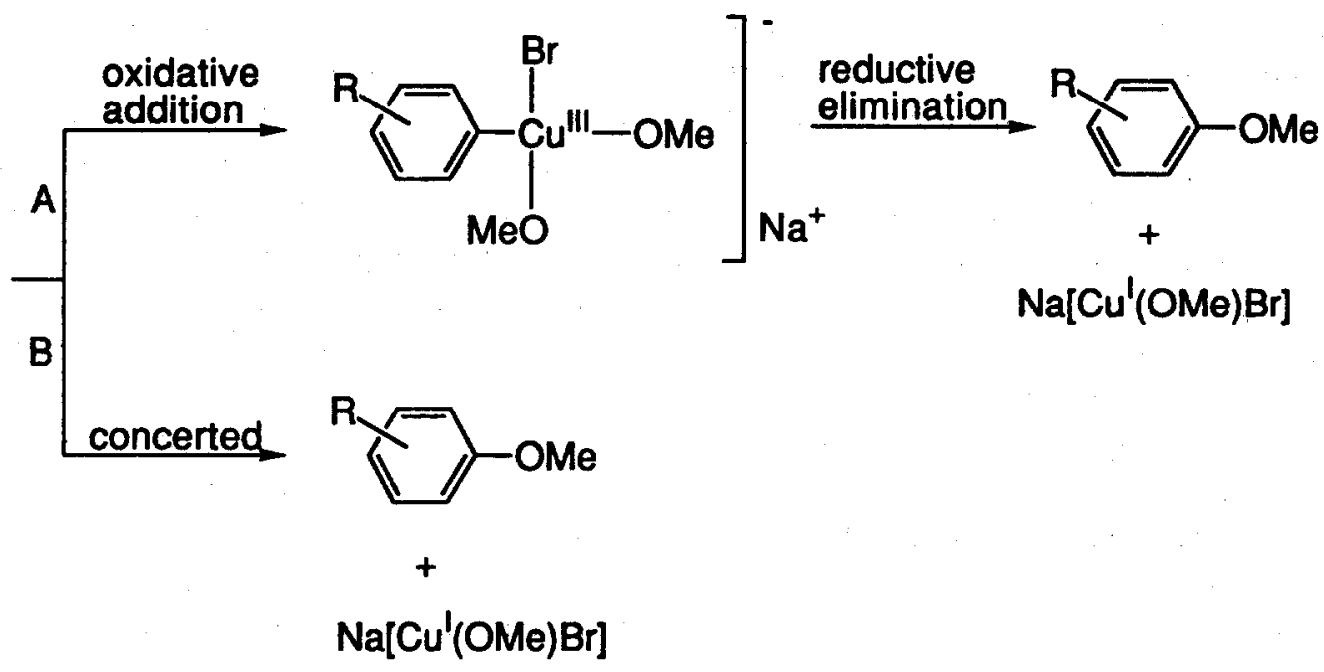

Scheme 3. Proposed mechanism of the copper catalysed reaction of aryl bromides with sodium methoxide. 
was finished within $30 \mathrm{~min}$. An alternative faster method using solid sodium methoxide was also developed (reaction 46, see experimental)

When no methanol was added to the DMF reaction mixture (47) the formation of anisole was poor, presumably some methanol is necessary to enable the reaction because of its ability to dissolve sodium methoxide (not all methanol is distilled off in reaction 45!).

With the aim to further improve the substitution reaction (to enable the use of chlorobenzene instead of bromobenzene) the use of other cosolvents with an amide function was also investigated in the reaction with bromobenzene using solid sodium methoxide. When $N$-methylpyrilidinone (48) or 1,3-dimethylimidazolidone (49) were used instead of DMF the reaction proceeded even faster. These reactions have the disadvantage that they are exothermic and therefore difficult to control. Consequently these solvents cannot be recommended for the synthetic procedure with bromobenzene. The reaction carried out with tetramethylureum (TMU, reaction 50) was somewhat slower than the DMF reaction (46).

Since in the competition reactions no severe difference in reactivity between bromobenzene and the aryl bromides used (p-OMe-, m-OMe-, p-Me-, m-Me-, p-Cl- and m-Cl-bromobenzene) was found we assume that this synthetic procedure is of general nature when aryl bromides are used without strong electron withdrawing substituents.

\section{Possible chloride substitution}

The copper catalysed nucleophilic aromatic substitution reaction of sodium methoxide with chlorobenzene was attempted using the optimal conditions for the bromobenzene substitution reaction with $\boldsymbol{N}$-methylpyrilidinone as a solvent. After 1 hour this reaction yielded only $4 \%$ of anisole and thereafter this amount did not increase. However a considerable amount of benzene (16\%) was formed in this reaction mixture after 6 hours. This result indicates that the carbon-chlorine bond is activated but that instead of the substitution reaction reduction is taking place.

It has been found with aryl halides that chlorine substitution is far more difficult in copper catalysed reactions. This is most readily explained by the more diffuse $n$-electrons of bromine and iodine derivatives compared to those of the chlorine derivatives. The more diffuse $n$-electrons of the bromine and iodine derivatives are able to improve the complexation step (leading to intermediate III, Scheme 3) and/or the intimate electron transfer step (leading to intermediate IV). It can therefore be understood that either of these two steps are impossible (or proceed very slow) in the copper catalysed nucleophilic aromatic substitution reaction of sodium methoxide with chlorobenzene. The low conversion of chlorobenzene is thus in good agreement with our proposed reaction mechanism.

\section{EXPERIMENTAL}

\section{General}

Reactions were carried out under dry oxygen-free nitrogen using standard Schlenk tochniques. Solvents were carefully dried and distilled prior to use. Aryl bromides (Merck) were distilled and stored under nitrogen. Metal salts were generally used as commercially available ( $\mathrm{CuBr}, \mathrm{CuCl}_{2}$ from Aldrich; copper powder, $\mathrm{LiBr}, \mathrm{NaBr}, \mathrm{NaOAc}$ fron Merck; copper phthalocyanine from Fluka: CoBr2 from Ventron). $\mathrm{CuCl},{ }^{12} \mathrm{CuBr}, 13$ (incidently used freshly prepared) copper(I) benzoate 14 and copper(II) methoxide 15 were synthesised according to literature procedures and stored under nitrogen in the dark. The 5.4 M NaOMe in methanol solutions were obtained from BASF or Dynamit Nobel. The sodium methoxide solutions used in the competition reactions was synthesized from solid sodium methoxide and methanol. Solid NaOMe was obtained from BASF and titrated prior to use (content always $>99.9 \%$ ). 


\section{Geperal reaction procedures}

The reagent combinations used are liated in Tuble I. To a three-necked roction fiak (250 mL) equipped with a cooler (with a nitrogen in/out-let) and a thermometer were added the aryl bromide, codium methoxide and the other solvents or additives at ambient

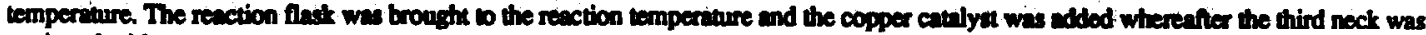
equipped with a serum cap.

\section{Competition reactions}

To a three-necked reaction finsk (250 mL) equipped with a cooler (with a nitrogen in/out-let) and a thermometer were added bromobenzene $(7.85 \mathrm{~g}, 50 \mathrm{mmol}, 5.16 \mathrm{~mL})$, the aryl bromide $(50 \mathrm{mmol})$, the internal reference mesitylene (1.2 $\mathrm{g}, 10 \mathrm{mmol}, 1.39$ $\mathrm{mL}$ ) and sodium methoxide ( $1 \mathrm{~mol}, 185 \mathrm{~mL}$ of a $5.4 \mathrm{M}$ solution in methanol). The resction mixture was brought to the reflux cemperature $\left(92^{\circ} \mathrm{C}\right)$ whereafter the copper catalyst $(10 \mathrm{mmol}, 1.44 \mathrm{~g})$ was added and the third nock was oquipped with a senum cap.

\section{Analysis of products}

Reactions were followed by taking sumples of the reaction mixture through the serum cap with syringe technigues and then suspending the samples in dichloromethane. After deposition of the copper salts the products in the dichloromethane layer were quantitatively analyaed by gas-liquid chromatography (GLC) on Perkin Elmer F17 gas chromatograph using a 9\% Apiezon and 1\% carbowax column ( $1 \mathrm{~m} \times 1 / 8$ inch; flow $10 \mathrm{~mL} \mathrm{~N} 2 / \mathrm{min}$ ).

Analysis of the organic products after the competition reactions was carried out by combined GC-MS and GLC analysis. The GC-MS analysis were recorded on a Kratos MS 80 combined gas chromatograph-mass spectrometer (BP I column (S.G.E.); $25 \mathrm{~m} \times 0.33 \mathrm{~mm}$ x $0.5 \mu$; flow $2 \mathrm{~mL} / \mathrm{min}$; split various). The mass spectn were recorded at an ionizing voltage of $40 \mathrm{eV}$.

The conversion pencentages were calculated from peak areas using internal standard techniques and had an accuracy of \pm 2 rel. \%.

Synthesis of anisole

Using solid sodium methoxide.

At ambient temperature solid sodium methoxide (16.2 g. $300 \mathrm{mmol}$ ) was added to a solution of bromobenzene (31.4 g. $200 \mathrm{mmol}$, $21.0 \mathrm{~mL}$ ) in dimethyl formamide $(50 \mathrm{~mL})$ and methanol $(20 \mathrm{~mL})$ in a three-necked reaction flask (250 mL) equipped as for the general reaction procedure described above. The temperature of the reaction flask was raised $10110^{\circ} \mathrm{C}$ and copper(I) bromide $(2.9 \mathrm{~g}, 20 \mathrm{mmol})$ was added. After $45 \mathrm{~min}$ the reaction was stopped by cooling the reaction mixture to room temperature. The reaction mixture was then poured into $200 \mathrm{~mL}$ of water and the anisole extracted by washing with dichloromethane. The organic layer was dried with magnesium sulphate and after concentration on a rotary evaporator the anisole was separated by distillation (bp 156-158 ${ }^{\circ} \mathrm{C}$; yield $95 \%$ ).

\section{Using $5.4 M$ sodium methoxide solution in methanol.}

At ambient temperature was added a $55.5 \mathrm{~mL}$ of a $5.4 \mathrm{M}$ solution of sodium methoxide in methanol $(55.5 \mathrm{~mL}, 5.4 \mathrm{M}, 300 \mathrm{mmol})$ to a solution of bromobenzene $(220 \mathrm{mmol}, 21.0 \mathrm{~mL})$ in dimethyl formanide $(50 \mathrm{~mL})$ in a three-necked reaction flask (250 mL) equipped with a Dean and Stark apparatus. The temperature of the reaction flast was raised to $110^{\circ} \mathrm{C}$ while methanol was allowed to distil off and was collected in the Dean and Stark apparatus. Copper(I) bromide $(2.9 \mathrm{~g}, 20 \mathrm{mmol})$ was then added to the reaction mixture. During the reaction (at $110^{\circ} \mathrm{C}$ ) methanol was continuously distilled off. Reaction time, work-up and isolation of anisole were identical to the synthesis using solid methoxide (vide supra).

\section{References}

1) L. Testaferri, M. Tiecco, M. Tingoli, D. Chianelli, M. Montanucci, Synthesis, 751 (1983).

2a) Meisenheimer, Justus Liebigs Ann. Chem., 323, 205 (1902); b) R.K. Norris, in "The Chemistry of Functional Groups", S. Patai and Z. Rappoport, ed., J. Wiley and Sons, N.Y., 1983, Suppl. D. ch. 16, p. 681.

3a) J.E. Shaw, D.C. Kunerth, S.B. Swanson, J. Org. Chem., 41.732 (1976); b) L. Testaferri, M. Tiecco, M. Tingoli, D. Chianelli, M. Montanucci, Tetrahedron, 39, 193, (1983).

4a) R.G.R. Bacon, O.J. Stewart, J. Chem. Soc.(C), 301 (1969); b) R.G.R. Bacon, S.C. Rennison, J. Chem. Soc.(C), 308 (1969); c) R.G.R. Bacon, S.C. Rennison, J. Chem. Soc.(C), 313 (1969); d) R.G.R. Bacon, J.R. Wright, J. Chem. Sac.(C), 308 (1969).

5) V.V. Litvak, S.M. Shein, Zh. Org. Khim., 10, 2360, Eng. ed. p. 2373, (1974).

b) G.M. Whitesides, J.S. Sadowski, J. Lilbum, J. Am. Chem. Sac., 96, 2829 (1974).

7) J. Lindley, Tetrahedron, 40, 1433 (1984) and references cited therein.

8) WJ. Moore, Physical Chemistry, ed. Longman, London, 1978, Ch. 9.

9) R.W. Turner, E.L. Amma, J. Am. Chem. Soc., 85, 4046 (1963).

10) P.F. Rhodesiler, EL. Amma, J. Chem. Soc., Chem. Commun., 599 (1974).

11) C. Amatore, M.A. Oturan, J. Pinson, J.M. Saveant, A Thitbault, J. Am. Chem. Sac., 107, 3451 (1978).

12) G. Braver, Handbuch der Praperativen Arorganischen Chemie, ed., Enke, Stuttgart; 1981, p. 972.

13) ibid., p. 973.

14) D.A. Edwards, R. Richards, J. Chem. Soc, Dalton Trans., 2463 (1973).

15) C.H. Brulaker, J. Inorg. Nucl. Chem., 27, 59 (1965). 